\title{
Population Briefs, Vol. 20, no. 1
}

Population Council

Follow this and additional works at: https://knowledgecommons.popcouncil.org/ series_newsletters_popbriefs How does access to this work benefit you? Let us know!

\section{Recommended Citation}

Population Briefs 20(1): New York: Population Council, 2014. 

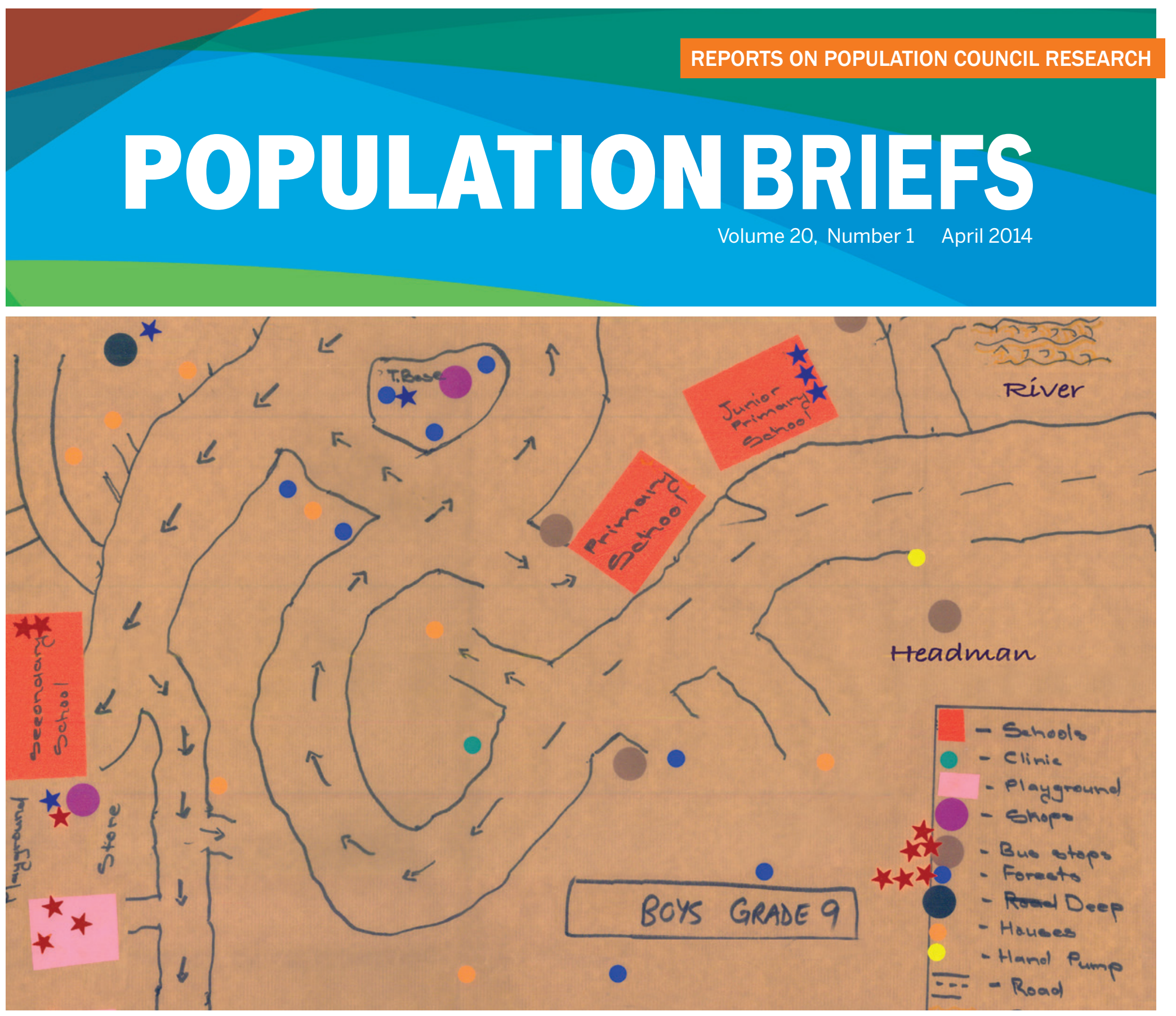

Boys and girls in South Africa drew maps of their neighborhoods and indicated how safe they felt in each location. The researchers found that after puberty, girls feel much less safe and begin to restrict their movements. See story, page 2.

\section{NS I DE}

"Anything Can Happen Anytime":

Perceived Lack of Safety among Girls in South Africa .2

Expanding Contraceptive Options for Breastfeeding Women: Introduction of the Progesterone Contraceptive Vaginal Ring. . .4

Reducing Unmet Need for Contraception:

Helping Women to Continue Effective Use ..6

Estimating the Size of Key Populations in Nairobi, Kenya .8 


\section{"Anything Can Happen Anytime": Perceived Lack of Safety among Girls in South Africa}

A novel study conducted by the Population Council and partners in South Africa has shown that teenage girls restrict their own movement in public areas substantially more than same-age boys, younger girls, and younger boys. None of the girls of any age rated any place in their community as more than "somewhat safe." The study, which employed "participatory mapping" among boys and girls in both rural and urban areas, suggests that self-restriction of movement among girls at puberty may result from an increased perception of their risk of experiencing violence or harassment in the community.

Population Council researchers collaborated with the Crime Reduction in Schools Project (CRISP) Trust, the KwaZulu-Natal Department of Education, and the United Nations Children's Fund (UNICEF) to explore the relationship between the violence adolescents perceive and their use of public spaces by sex, grade, and urban-rural residence. The exercise was conducted in rural and urban areas in South Africa's KwaZulu-Natal province among girls and boys in grade 5 (who ranged in age from 9 to 13 years) and grades 8-9 (ages 13 to 17 years).

Participants were asked to draw the area that represented the geographic space where they could freely roam. After identifying specific places within those areas — such as clinics, taxi stands, schools, and police stations - participants rated the safety of each place using the following categories: extremely safe, very safe, somewhat safe, sometimes safe/sometimes unsafe, somewhat unsafe, very unsafe, or extremely unsafe.

Analysis of the completed maps showed that urban girls perceived more extreme threats to their safety than did rural girls. Boys in rural areas, however, felt less safe than their urban male peers.
At younger ages, boys' and girls' maps of their communities were roughly equivalent in size. But in both rural and urban areas, the areas mapped by older girls were substantially smaller than those mapped by same-age boys, younger girls, and younger boys. The communities mapped by older boys were largest of all groups. For example, the self-defined community of rural grade 8-9 girls was just one-sixth that of rural grade 8-9 boys from the same school ( 0.90 square miles versus 5.46 square miles).

The study indicated that older girls perceive more dangers in their communities than younger girls and same-age and younger boys, particularly an increased vulnerability to sexual assault. On average, older girls were more likely than younger girls, or boys of the same age, to describe spaces in their area as very unsafe or extremely unsafe. This perceived threat increases the likelihood that girls will choose to or be pressured by their family to withdraw from

\section{"Maps often have}

political clout. They are a primary language of policy and politicians."

their communities. Girls reported, "Anything can happen anytime," suggesting that they feel hopeless and helpless.

The study's authors acknowledge some limitations of the participatory mapping method, including difficulty in direct comparisons across maps crafted with few pre-set criteria. (The researchers facilitated map comparisons by identifying key landmarks on the hand-drawn maps and plotting them on satellite-generated maps.)

\section{Using maps to promote change}

Perceptions of danger can be reduced by actually making communities safer and more welcoming, especially to girls. The authors state that mapping exercises of this sort, which clearly show how, where, and at what age girls feel their world is becoming less safe — and, thus, shrinking - could play a role in galvanizing action by politicians and community members.

When presented to local leaders — school administrators, police, and community leaders - the maps raised awareness about spaces deemed unsafe and helped to identify spaces, such as libraries, that could be turned into safe spaces for adolescents. In safe spaces, young people can gather, learn, and build healthy social support networks that they can draw upon in times and places of danger or insecurity.

"Maps often have political clout," says Population Council researcher Kelly K. Hallman, who led the study. "They are a primary language of policy and politicians."

\section{SOURCE}

Hallman, Kelly K., Nora J. Kenworthy, Judith Diers, Nick Swan, and Bashi Devnarain. 2013. "The contracting world of girls at puberty: Violence and genderdivergent access to the public sphere among adolescents in South Africa." Poverty, Gender, and Youth Working Paper No. 25. New York: Population Council.

\section{FUNDING}

UNICEF, UK Department for International Development (DFID), William and Flora Hewlett Foundation, the Bill \& Melinda Gates Foundation, and the U.S. National Institutes of Health (NIH) 


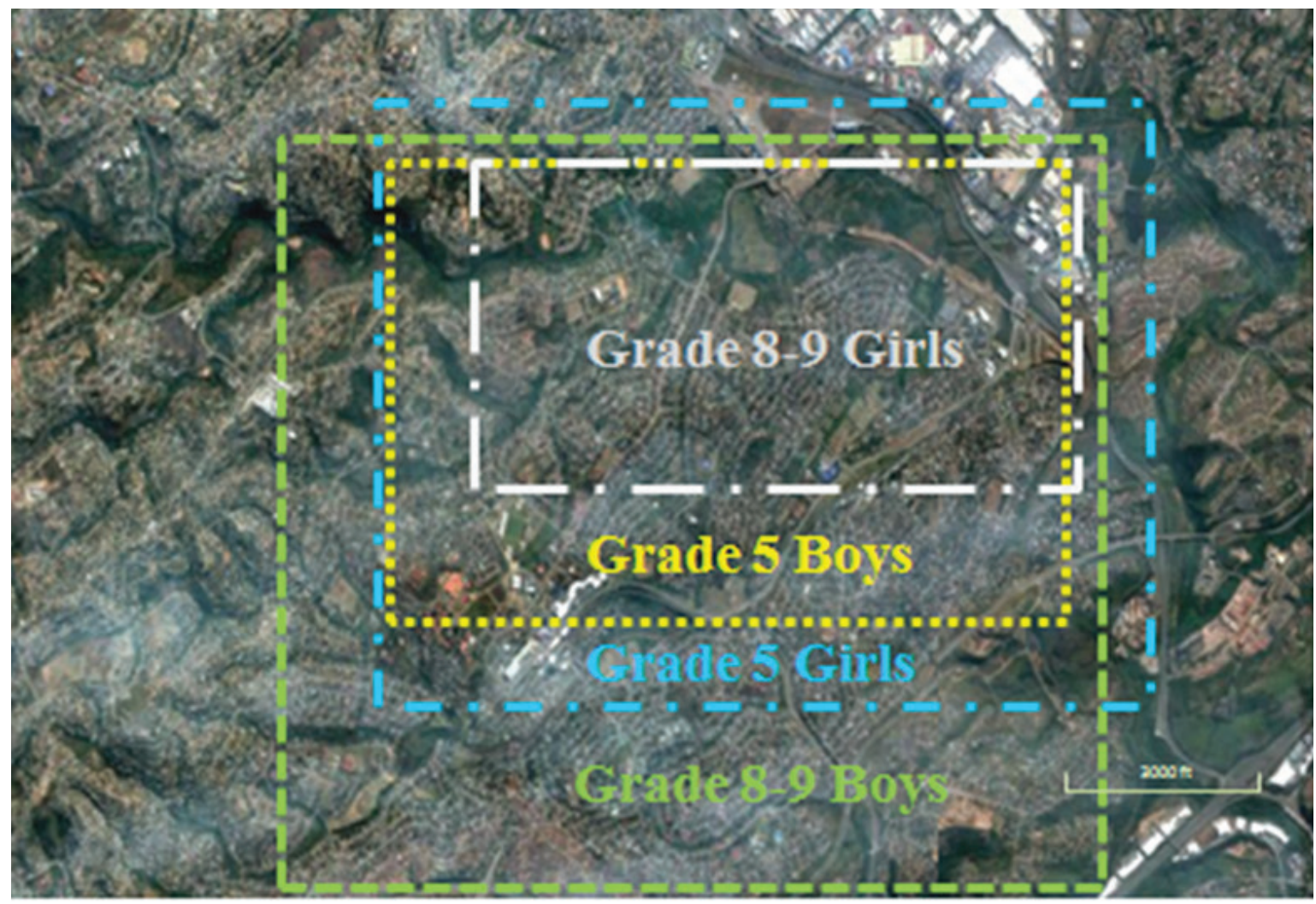

In both rural and urban (above) areas, the areas mapped by older girls were substantially smaller than those mapped by same-aged boys and younger girls and boys.

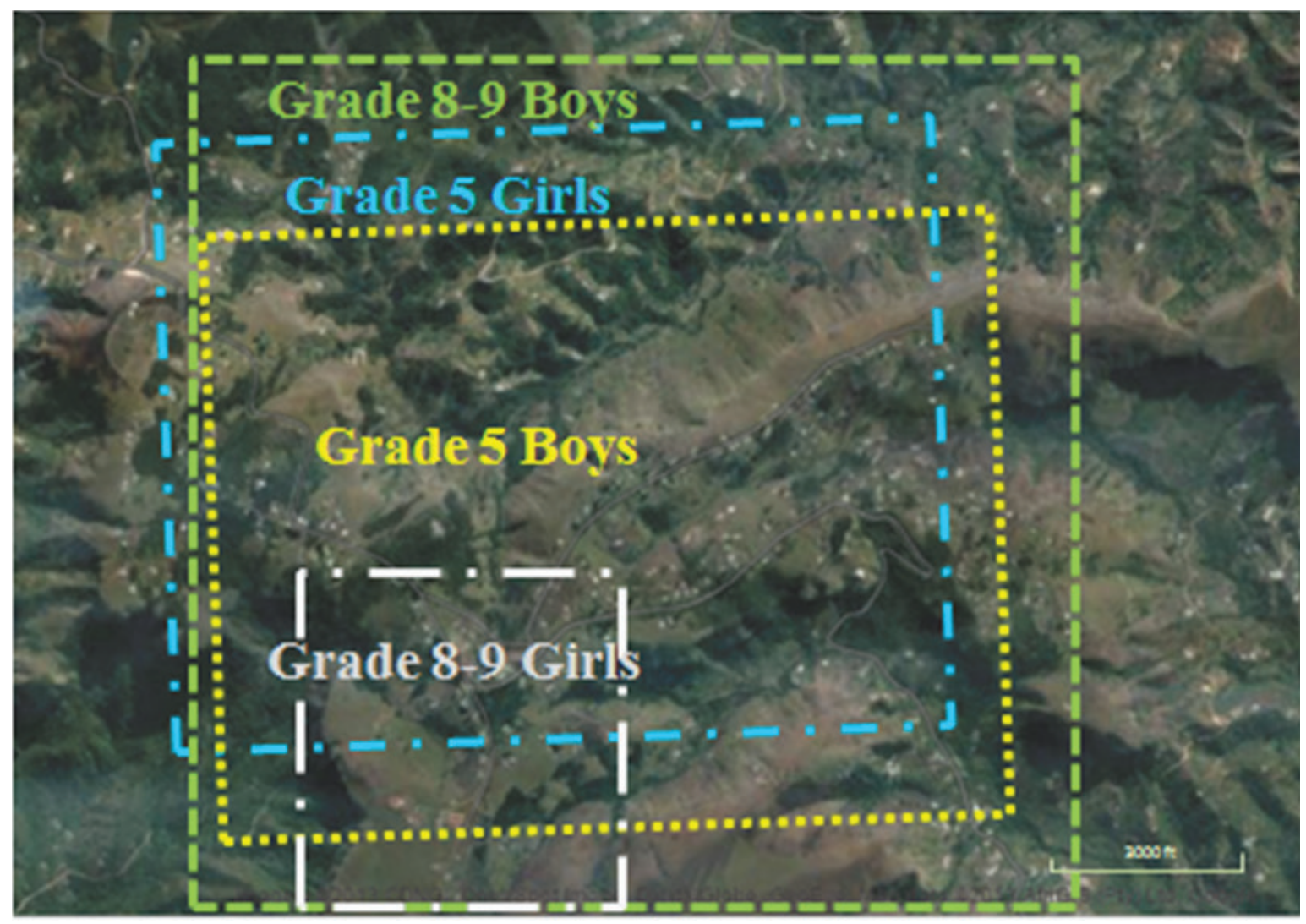

The self-defined community of rural grade 8-9 girls was just one-sixth that of rural grade 8-9 boys from the same school. 


\section{Expanding Contraceptive Options for Breastfeeding Women: Introduction of the Progesterone Contraceptive Vaginal Ring}

For the first several months after childbirth, exclusive breastfeeding is generally an effective method for delaying a subsequent pregnancy. Many postpartum women, however, do not or are not able to breastfeed exclusively. Once a woman begins supplementing her infant's diet, stops breastfeeding, or resumes menstruation, she should use a family planning method if she wishes to space or limit childbearing.

In low-resource settings, breastfeeding postpartum women who wish to delay the next pregnancy often have limited options to access effective contraceptive methods that can be used during this time period. To address this need and expand safe and effective choices, the Population Council and partners developed the progesterone contraceptive vaginal ring (PCVR). It is made of silicone with progesterone dispersed throughout. Women insert this ring into the vagina, where it slowly releases a continuous low dose of the natural hormone progesterone which reinforces the inhibitory effect of breastfeeding on ovulation to prevent pregnancy and delays the return of menstruation. Each PCVR can be used continuously for three months, with additional vaginal rings used in succession for up to one year as long as the woman breastfeeds at least four times a day. The PCVR can be inserted and removed by the woman herself, reducing the need for involvement by skilled health care providers, and fertility returns rapidly after a woman stops using the ring.

Studies in numerous countries have shown that the PCVR is as effective as an intrauterine device (IUD) in preventing pregnancy as long as the woman is breastfeeding at least four times a day. Results have also demonstrated that the PCVR is safe for both mothers and babies and does not affect breast milk production. Currently the PCVR is approved and available in several Latin American countries, but it has the potential to be a useful option for more than 25 million breastfeeding women living in low-resource settings. A recent commentary by Population Council researchers published in Contraception makes the case for introducing the PCVR more widely in these settings and outlines the factors that will need to be addressed to ensure successful introduction of the ring.

\section{Policy considerations}

Like all health technologies, the PCVR can only be introduced and made available successfully when there is a supportive policy and regulatory environment. In their analysis, the authors of the Contraception commentary recommend:

- educating national health policymakers about the PCVR, so they fully understand the technology, and how this contraceptive can fill a key niche in providing comprehensive family planning services and promoting maternal and child health;

- establishing how the PCVR will be dispensed and by whom (for example, by community health workers or higher-level care providers only);

- considering and identifying potential procurement and financing possibilities; and

- obtaining World Health Organization (WHO) prequalification of the ring manufacturing, a common prerequisite among international procurers, which may support the provision of the PCVR.

\section{Preparing the service environment}

To ensure a smooth introduction of the technology once it is approved in various countries, several steps will need to be taken to prepare the service environment, including:
- preparing and training clinic staff and providers about client counseling, PCVR insertion, and the conditions under which the product is effective

- reviewing, evaluating, and modifying service guidelines, protocols, and practices

- providing information about the PCVR to obstetricians and gynecologists, nurses and midwives, pharmacists (including those in the private sector), and potential users

\section{Ensuring user acceptability}

Even if the policy and service environments are supportive, women will only use the PCVR if they like it. Confirming acceptability is especially important because the PCVR is a different type of method compared with others commonly used by breastfeeding women, such as injectables and progestin-only pills. In the commentary, the authors cite data indicating that women generally find the PCVR easy to use, comfortable, and well-tolerated. Such data are encouraging and data from ongoing

\section{"The PCVR is as}

\section{effective as an}

intrauterine device

(IUD) in preventing

pregnancy as long

as the woman is

breastfeeding at least

four times a day." 


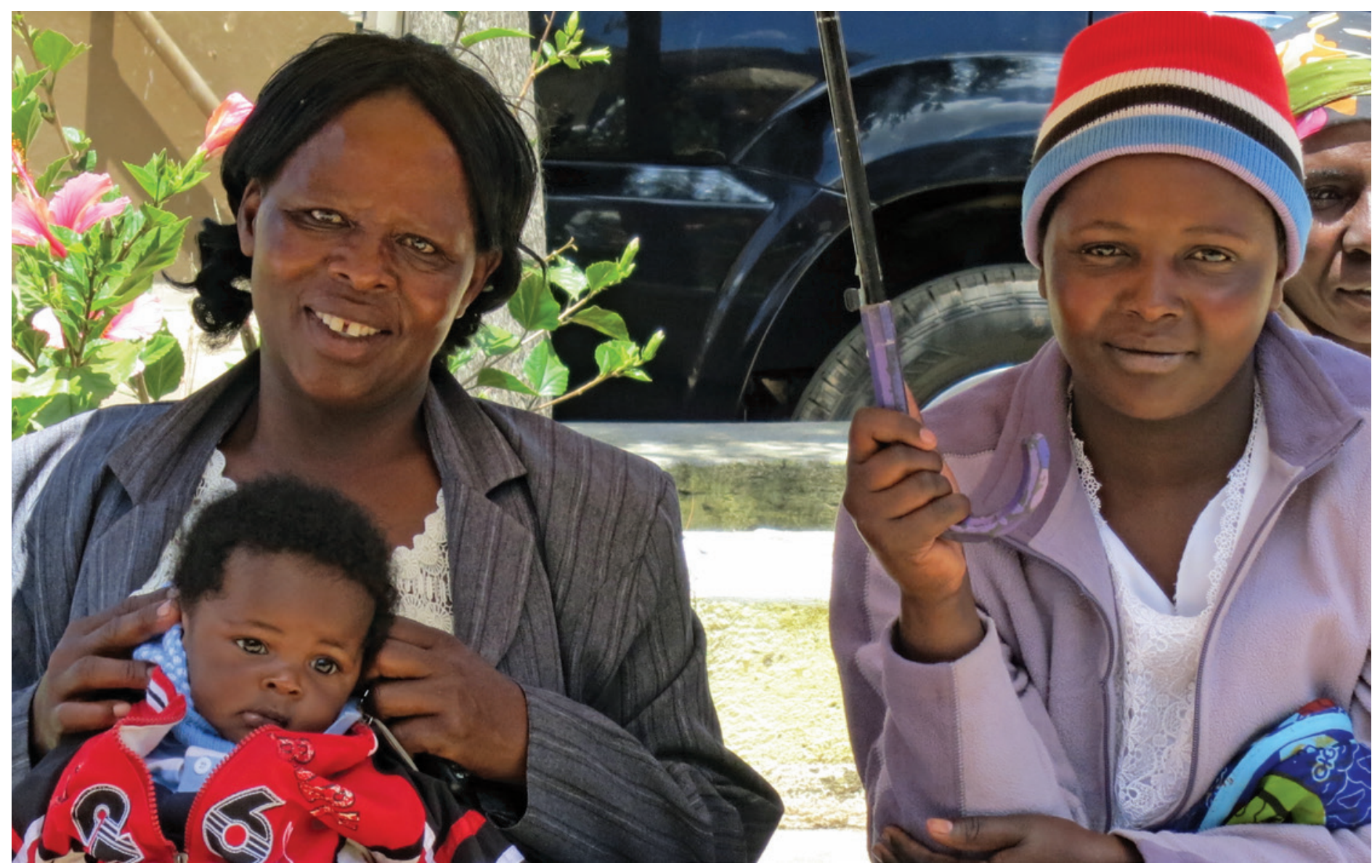

Once a woman begins supplementing her infant's diet, stops breastfeeding, or resumes menstruation, she should use a family planning method if she wishes to space or limit childbearing.

acceptability studies in India, Kenya, Nigeria, and Senegal will provide more information about women's preferences.

\section{Council studies to facilitate PCVR introduction}

Although the PCVR is available to women in seven countries in Latin America, it is not yet approved for use in sub-Saharan Africa or Asia, where it has great potential for meeting the contraceptive needs of breastfeeding women. The Population Council is collaborating with partners in India, Kenya, Nigeria, and Senegal, to obtain regulatory approval and promote product introduction. The Council's goal is to expand access to the PCVR in additional countries where there is a high unmet need for modern contraceptive technologies for postpartum, breastfeeding women. Council researchers involved in the studies in Africa are:

- assessing interest in and support for the PCVR among policymakers, regulators, and others who determine which products are made available in their countries;

- determining the acceptability of this ring among breastfeeding women, their partners, and providers; and

- identifying and streamlining pathways for introducing the product if approved and understanding the market and product placement opportunities.

The Council is also conducting assessments in each country to determine the most appropriate sectors (public, private, non-profit, social marketing) in which to make the PCVR available. One of these initiatives is a market segmentation analysis using Demographic and Health Survey (DHS) data to determine the characteristics of women who may want to use the PCVR.

If the PCVR appears to have an appropriate role in the method mix of various countries, the Council will develop an introductory plan to bring the product into these and other low-resource settings, further contributing to the goal of reducing unmet need for contraception.

\section{SOURCE}

RamaRao, Saumya, Heather Clark, Ruth Merkatz, Heather Sussman, and Régine Sitruk-Ware. 2013. "Progesterone vaginal ring: Introducing a contraceptive to meet the needs of breastfeeding women," Contraception 88 (5): 591-598. 


\section{Reducing Unmet Need for Contraception: Helping Women to Continue Effective Use}

In the developing world, 222 million women would like to delay or avoid pregnancy, but are not using modern contraception. At the 2012 London Summit on Family Planning, the development community committed to reducing this unmet need for modern contraception by reaching 120 million women and girls from 69 of the world's poorest countries with voluntary access to family planning information, contraceptives, and services by 2020, an agreement known as FP2020. In a recent study,
Population Council researchers recommend a promising strategy for reducing unmet need for modern contraception. Rather than focusing solely on reaching women who have never used contraception, the researchers suggested providing better information and services to support women who already use contraceptives, and making it easier for those who previously used contraception to resume use.

Council researchers Anrudh K. Jain, Francis Obare, Saumya RamaRao, and Ian
Askew analyzed Demographic and Health Survey (DHS) data compiled in 34 developing countries between 2005 and 2010. Twenty of these countries were in sub-Saharan Africa.

Drawing from the data, the authors estimated that among the 120 million women whom FP2020 seeks to reach are some 45 million women who once used contraceptives, but discontinued. Additionally, in the coming years, if current levels of contraceptive discontinuation continue, 49 million current contra-

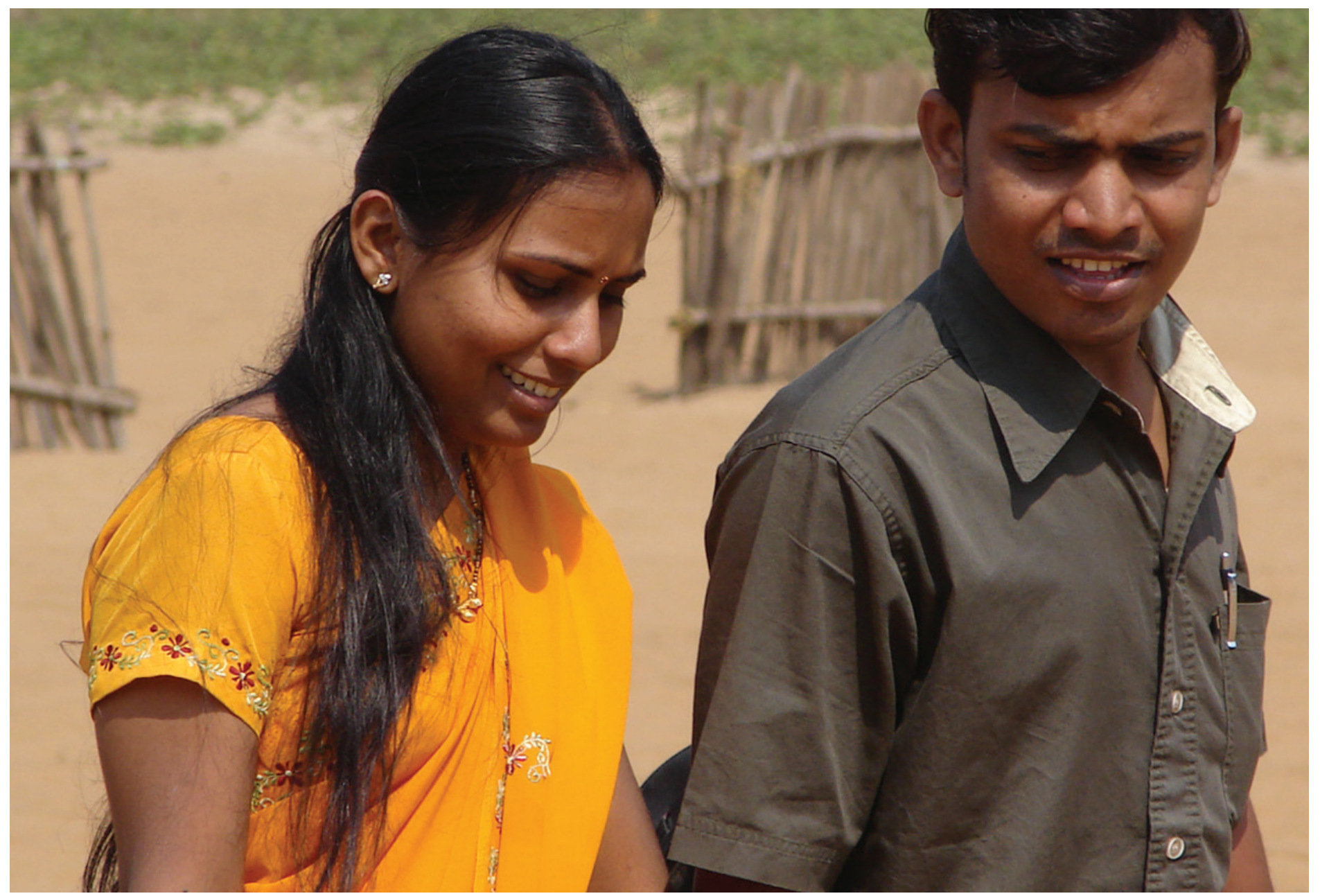

High contraceptive discontinuation could leave up to 94 million women with unmet need for contraception. 


\section{"Engaging women}

\section{who bave used a}

\section{method in the past or}

are using one now is

likely to be the fastest

and most cost-effective

way to reduce unmet

need."

ceptive users would stop using contraceptives, even though they still wish to avoid pregnancy. Therefore, the researchers estimated that high contraceptive discontinuation in the past and present could leave up to 94 million (45 million + 49 million) women with unmet need. This study is the first to empirically estimate the potential contribution of high contraceptive discontinuation to current and future unmet need.

According to the authors, reducing unmet need could best be achieved in two ways. First, by supporting women and girls who are already using a modern contraceptive method with good information and services so that they can continue with their current method or switch to another modern method that better suits their needs. And second, by helping women and girls who once used, but no longer use, a modern contraceptive method to find and use a method that suits their needs.

"Engaging women who have used a method in the past or are using one now is likely to be the fastest and most costeffective way to reduce unmet need," says Jain, "because these women have already evaluated potential advantages and overcome barriers to contraceptive use-including everything from cultural and social attitudes to out-of-pocket cost—and have made decisions in favor of family planning and adopted a method."

\section{Strategies to promote sustained and consistent contraceptive use}

The authors identified three strategies for reducing contraceptive discontinuation, increasing switching to more effective methods, and increasing uptake by former users. One strategy is to expand the range of contraceptive methods available so that women have more options to choose from; this and other studies have shown that the more contraceptive methods that are available, the less likely a woman is to discontinue contraceptive use. The second strategy is to improve quality of care and provider-client interactions; studies have shown that women are more likely to continue using contraception and less likely to experience unintended pregnancy when they receive higher-quality counseling and care. The third proposed strategy focuses on improving the characteristics of contraceptive technologies available; this approach assumes that women will continue using their preferred method, or decide to return to it, if products are easier to use, well-tolerated, and more affordable.

"Focusing on encouraging past users with unmet need to resume use and supporting current users are essential in reducing unmet need in the future and reaching FP 2020 goals," says Askew.

\section{SOURCE}

Jain, Anrudh K., Francis Obare, Saumya RamaRao, and lan Askew. 2013. "Reducing unmet need by supporting women with met need," International Perspectives on Sexual and Reproductive Health 39(3):133-141. DOI: 10.1363/3913313.

FUNDING

UKaid/DFID
Jain, Obare, RamaRao, and Askew found that in the 34 countries they studied:

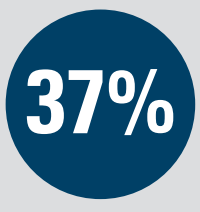

of women had no

need for contra-

ception because

they wanted to become pregnant or were menopausal;

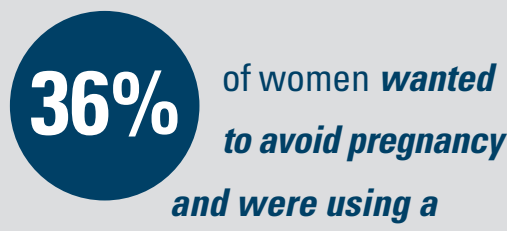

modern method at the time of the survey;

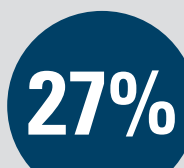

of women had an unmet need because they wanted to avoid pregnancy but were not currently using contraception;

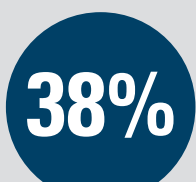
of women with current unmet need had used a modern method in the past, but were not currently using contraception; and

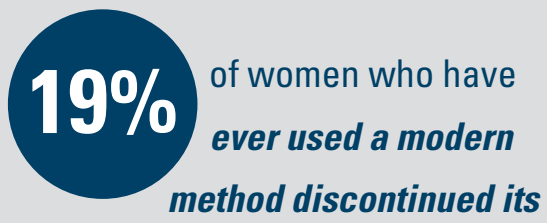

use, but continue to have an unmet need. 


\section{Estimating the Size of Key Populations in Nairobi, Kenya}

A team of researchers, including three from the Population Council, have developed estimates of the sizes of three key populations at risk for HIV infection in Nairobi, Kenya: men who have sex with men, female sex workers, and people who inject drugs. These estimates are among the first solid data on the size of these populations in Nairobi, providing practitioners with evidence to inform the development of programs that meet the needs of these vulnerable groups.

HIV disproportionately affects men who have sex with men, female sex workers, and people who inject drugs. All three groups are stigmatized, discriminated against, and face legal, social, and economic barriers to accessing health services. Because of these circumstances, people in these populations often remain hidden and they may not seek the prevention and treatment services they need to safeguard their own health and the health of their sexual and drug-injecting partners.

\section{Dearth of data}

Before this study, policymakers and program planners lacked realistic estimates of the size of these groups, and such limitations restricted their ability to understand the scope of the HIV epidemic and allocate scarce resources appropriately. This evidence about the size of marginalized populations will allow policymakers to respond to the HIV epidemic more effectively.

A gold-standard population data source, such as a census, does not exist for men who have sex with men, female sex workers, or people who inject drugs. So the researchers used three other methods to calculate the size of these populations. Because these approaches are not randomized, the data they produce might be biased in one direction or another. Employing multiple approaches reduces the chance of bias. The approaches were incorporated within a behavioral surveillance study of key populations funded by the U.S. Centers for Disease Control and Prevention (CDC) in Nairobi. The three approaches were:

- the multiplier method, which gathers data on use from various services, projects, and studies and compares them to reported service use in the surveillance survey;

- the "Wisdom of the Crowds" method, which asks respondents from specific groups to estimate how many members of their population exist, resulting in an average or median estimate of the total population size; and

- a literature review to identify published estimates of the size of the three populations in contexts and regions similar to Nairobi.

"We were able to access service data from a number of sources in this study, which in turn provided a range of estimates," said Scott Geibel, a Council researcher on the study. "We then convened stakeholders to review these data and decide on the most plausible estimate and ranges."

\section{"These data offer HIV}

prevention program

planners some much-

needed precision in

key population size

estimates."
The behavioral surveillance study, which took place in 2010-2011, employed respondent-driven sampling (RDS) to recruit participants. RDS allows researchers to gain access to stigmatized populations through their social networks. Respondents referred a limited number of friends or acquaintances (who are also members of the key population) to participate in the study. The study involved 563 men who have sex with men, 593 female sex workers, and 263 people who inject drugs.

The study team validated the resulting estimates with experts from the Kenyan government, investigators, program managers, and advocates in Nairobi to determine whether the estimates seemed reasonable and to establish plausible upper and lower bounds for the size of the populations. Combining the three methods resulted in the most well-supported estimate of the sizes of key populations available. The researchers arrived at the following estimates for the size of the three populations in Nairobi:

- 11,042 men who have sex with men (with low and high ranges of 10,000 and 22,222);

- 29,494 female sex workers (with low and high ranges of 10,000 and 54,467); and

- 6,216 people who inject drugs (with low and high ranges of 5,031 and 10,937)

The authors acknowledged some basic limitations of their study, most of which related to varying definitions of group membership. For example, how often and recently should a man have had sexual relations with another man to be considered a member of the men who have sex with men group? And should a woman be considered a female sex worker if she has sex for money only occasionally, or only if this is her primary source of income? 


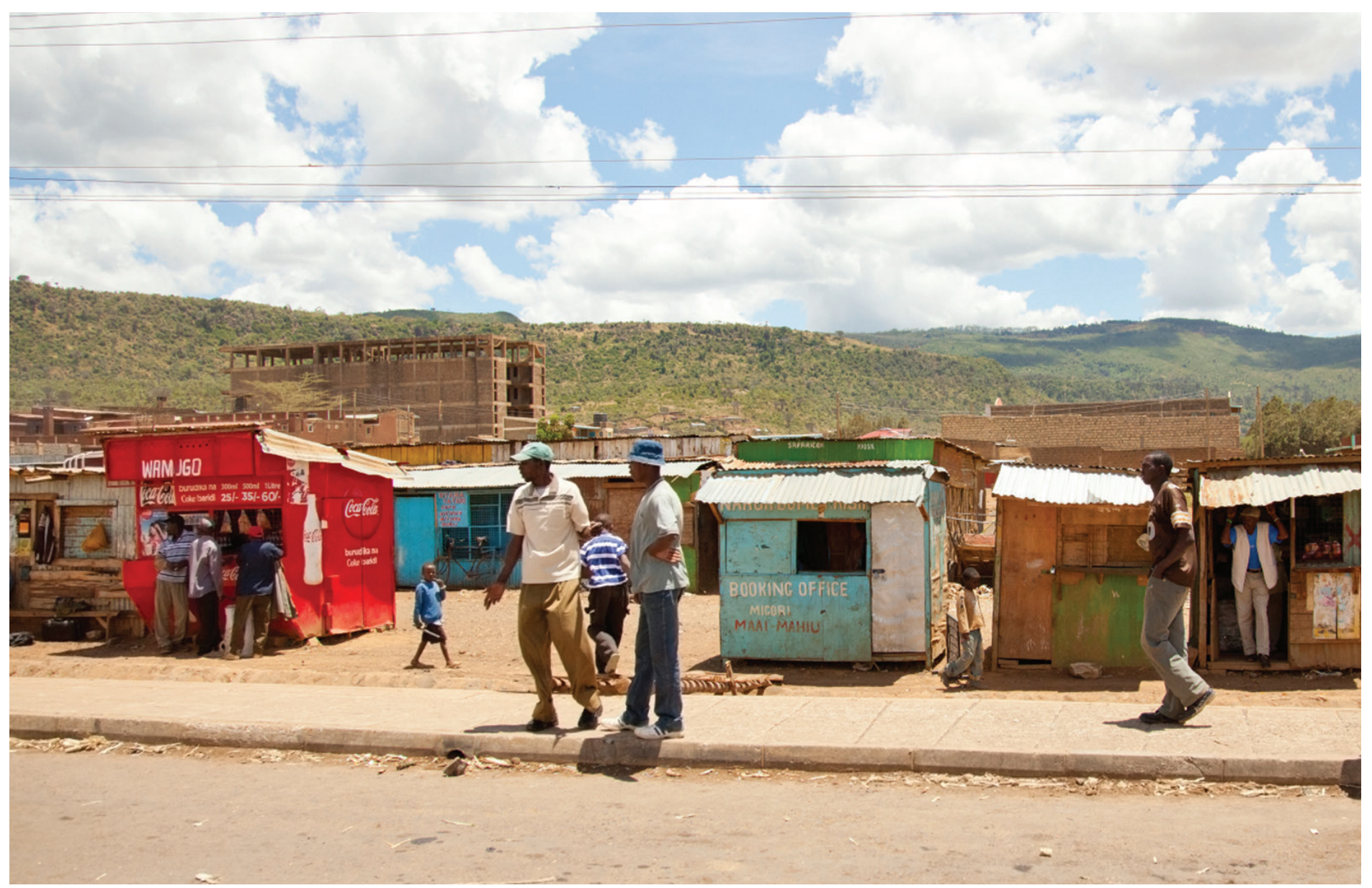

The study was one of the first to incorporate such a wide range of data sources and research methods within a broader HIV surveillance survey.

Nevertheless, the study was one of the first to incorporate such a wide range of data sources and research methods within a broader HIV surveillance survey. National government agencies, community-based organizations, and donor organizations can use these population size estimates to develop and launch HIV prevention, treatment, and care services. Further refinement of methods and estimates could also be undertaken. For the time being, this study clearly showed that significant numbers of men who have sex with men, female sex workers, and people who inject drugs live in Nairobi. They and their advocates now have evidence to help them campaign for greater resources to meet the health needs of these key populations.
"These data offer HIV prevention program planners some much-needed precision in key population size estimates," commented Population Council researcher Jerry Okal.

\section{SOURCE}

Okal, Jerry, Scott Geibel, Nicolas Muraguri, Helgar Musyoki, Waimar Tun, Dita Broz, David Kuria, Andrea Kim, Tom Oluoch, and H. Fisher Raymond. 2013. "Estimates of the size of key populations at risk for HIV infection: men who have sex with men, female sex workers and injecting drug users in Nairobi, Kenya." Sexually Transmitted Infections 89(5): 366-371. doi:10.1136/sextrans-2013-051071

\section{FUNDING}

U.S. Agency for International Development (USAID)/U.S. President's Emergency Plan for AIDS Relief (PEPFAR) and the U.S. Centers for Disease Control and Prevention (CDC)

\section{COLLABORATION}

This study was a collaboration among the following organizations:

- Casino STI Clinic

- U.S. Centers for Disease Control and Prevention

- Gay and Lesbian Coalition of Kenya

- Kenya AIDS Vaccine Initiative

- Liverpool Voluntary Counseling and Testing

- Nairobi Outreach Services Trust (NOSET)

- National AIDS and STD Control Programme (Kenya)

- National AIDS Control Council

- Population Council

- San Francisco Department of Public Health

- United Nations Office on Drugs and Crime (UNODC)

- University of California, San Francisco

- University of Manitoba's Sex Worker Outreach Programme (SWOP) 


\section{HIV AND AIDS}

Dube, Samukeliso, Barbara A. Friedland, Saiqa Mullick Martha Brady, and C. Elizabeth McGrory. "Policy and programme considerations for ARV-based prevention for women: Insights from key opinion leaders in Zimbabwe about tenofovir gel." New York and Johannesburg: Population Council.

Hardee, Karen, Jill Gay, Melanie Croce-Galis, and Amelia Peltz. "Strengthening the enabling environment for women and girls: What is the evidence in social and structural approaches in the HIV response?" Journal of the International AIDS Society 17(1): 18619

Hsu, Mayla, Meropi Aravantinou, Radhika Menon, Samantha Seidor, Daniel Goldman, Jessica Kenney, Nina R. Derby, Agegnehu Gettie, James Blanchard, Michael Piatak Jr., Jeffrey D. Lifson, Jose A. Fernandez-Romero, Thomas M. Zydowsky, and Melissa Robbiani. "A combination microbicide gel protects macaques against vaginal SHIV-RT infection, but only partially reduces HSV2 infection after a single high-dose co-challenge," AIDS Research and Human Retroviruses 30(2): 174-183.

Population Council. "Program and policy considerations for tenofovir gel in India: An overview," Project Brief. New York: Population Council.

"Setting the stage for ARV-based prevention for women: A snapshot of the Zimbabwean context," Program Brief. Johannesburg and New York: Population Council.

Prabhughate, Abhijit, Avina Sarna, and Martha Brady. "Tenofovir gel for HIV prevention for women: Perspectives of key opinion leaders from India," Health Policy and Technology 3(1): 59-65.

Sheehy, Meredith, Waimar Tun, Lung Vu, Sylvia Adebajo, Otibho Obianwu, and Andrew Karlyn. "High levels of bisexual behavior and factors associated with bisexual behavior among men having sex with men (MSM) in Nigeria," AIDS Care 26(1): 116-122.

\section{POVERTY, GENDER, AND YOUTH}

Austrian, Karen, Natalie Jackson Hachonda, and Paul C. Hewett. 2013. "The Adolescent Girls Empowerment Program: Lessons learned from the pilot test program." Lusaka: Population Council.

Engebretsen, Sarah. 2013. "Designing, implementing, and evaluating a targeted, evidence-based intervention for a vulnerable subgroup of girls: A case study of the Filles Éveillées (Girls Awakened) pilot program for migrant adolescent girls in domestic service in urban Burkina Faso," Case study. New York: Population Council. [also published in French]

2013. "Evaluation of Filles Éveillées (Girls Awakened): A pilot program for migrant adolescent girls in domestic service," Evaluation report. New York: Population Council. [also published in French]

2013. "Follow-up study of migrant adolescent girls in domestic service who participated in the first cohort of the Filles Éveillées (Girls Awakened) program," Technical report. New York: Population Council. [also published in French]

Kabore, Gisele. 2013. “Comprendre la vie des adolescentes avant et après la migration: Enquête réalisée sur les sites d'origine auprès d'anciennes filles migrantes employées comme aide-ménagères," Rapport technique. Ouagadougou: Population Council.
Kelly, Christine A., Paul C. Hewett, Barbara S. Mensch, Johanna Rankin, Samuel L. Nsobya, Sam Kalibala, and Pamela N. Kakande. "Using biomarkers to assess the validity of sexual behavior reporting across interview modes among young women in Kampala, Uganda," Studies in Family Planning 45(1): 43-58.

Mensch, Barbara S., Erica Soler-Hampejsek Christine A. Kelly, Paul C. Hewett, and Monica J. Grant. "Challenges in measuring the sequencing of life events among adolescents in Malawi: A cautionary note," Demography 51(1): 277-285

Sabarwal, Shagun, K.G. Santhya, and Shireen J. Jejeebhoy. "Women's autonomy and experience of physical violence within marriage in rural India," Journal of Interpersonal Violence 29(2): 332-347.

\section{REPRODUCTIVE HEALTH}

Acharya, Rajib and Shveta Kalyanwala. 2013. "Providers role in facilitating or impeding women's access to medical abortion: Evidence from Bihar and Maharashtra states, India, Programme Brief. New Delhi: Population Council.

Adongo, Philip Baba, Placide Tapsoba, James F. Phillips, Philip Teg-Nefaah Tabong, Allison Stone, Emmanuel Kuffour, Selina Esantsi, and Patricia Akweongo. 2013. "The role of community-based health planning and services strategy in involving males in the provision of family planning services: A qualitative study in Southern Ghana," Reproductive Health 10(36).

Agrawal, Praween Kumar, Kumudha Aruldas, and M.E. Khan. "Manual for monitoring and evaluation of behavior change communication (BCC) health programs." New Delhi: Population Council.

Agrawal, Praween Kumar, Kamla Gupta, Vinod Mishra, and Sutapa Agrawal. 2013. "Awareness on causes, consequences and preventive measures of obesity among urban married women in India," International Journal of Medicine and Public Health 3(4): 293-302.

. 2013. "Effects of sedentary lifestyle and dietary habits on body mass index change among adult women in India: Findings from a follow-up study," Ecology of Food and Nutrition 52(5): 387-406.

\section{. "A study on body-weight perception, future} intention and weight-management behavior among normalweight, overweight and obese women in India," Public Health Nutrition 17(4): 884-895.

Agrawal, Sutapa and Praween Kumar Agrawal. 2013 "Does rural to urban migration improve Indian women's health status and knowledge of AIDS," Asian Journal of Health Sciences 1(1): 8-16.

. 2013. "Induced abortion and women's reproductive health in India," Global Journal of Medicine and Public Health 2(5): 1-11.

. 2013. "Vitamin A supplementation among children in India: Does their socioeconomic status and the economic and social development status of their state of residence make a difference?" International Journal of Medicine and Public Health 3(1): 48-54.

Agrawal, Sutapa, Sayeed Unisa, and Praween Kumar Agrawal. 2013. "Pregnancies, abortion and women's reproductive health in rural Haryana, India," Journal of Nursing Science and Practice 3(1): 29-38.

. 2013. "Women's childhood experience: A perspective from rural Haryana, India," Journal of Human Behavior in the Social Environment 23(4): 437-461.
Amendah, Djesika D., Martin Kavao Mutua, Catherine Kyobutungi, Evans Buliva, and Benjamin Bellows. 2013. "Reproductive health voucher program and facility based delivery in informal settlements in Nairobi: A longitudinal analysis," PLoS ONE 8(11): e80582.

Bajracharya, Ashish, Benjamin Bellows, and Antonia Dingle. 2013. "Evaluation of a voucher programme in reducing inequities in maternal health utilization in Cambodia: A quasiexperimental study," The Lancet 381: s12.

Becker, Davida and Claudia Diaz-Olavarrieta. 2013. "Decriminalization of abortion in Mexico City: The effects on women's reproductive rights," American Journal of Public Health 103(4): 590-593.

Bellows, Benjamin, Claudia M. Conlon, Elizabeth S. Higgs, John W. Townsend, Matta G. Nahed, Karen Cavanaugh, Corinne G. Grainger, Jerry Okal, and Anna C. Gorter. 2013. "A taxonomy and results from a comprehensive review of 28 maternal health voucher programmes," Journal of Health, Population and Nutrition 31(4): S106-S128.

Bernie, Aaron M., E. Charles Osterberg, Peter J. Stahl, Ranjith Ramasamy, and Marc Goldstein. 2012. "Vasectomy reversal in humans," Spermatogenesis 2(4): 273-278.

"Day of dialogue: Mainstreaming emergency contraception in the National Family Welfare Program," meeting report. New Delhi: Population Council, 2013.

Densmore, Melissa, Benjamin Bellows, John Chuang, and Eric Brewer. 2013. "The evolving braid: How an organization in Uganda achieved reliable communications," Proceedings of the Sixth International Conference on Information and Communication Technologies and Development: Full Papers 1: 257-266

Dibaba Wado, Yohannes, Mesganaw Fantahun Afework, and Michelle J. Hindin. 2013. "Unintended pregnancies and the use of maternal health services in southwestern Ethiopia," BMC International Health and Human Rights 13: 36 .

Eichler, Rena, Kokila Agarwal, Ian Askew, Emma Iriarte, Lindsay Morgan, and Julia Watson. 2013. "Performancebased incentives to improve health status of mothers and newborns: What does the evidence show?" Journal of Health, Population and Nutrition 31(4): S36-S47.

Hardee, Karen, Jan Kumar, Karen Newman, Lynn Bakamjian Shannon Harris, Mariela Rodriguez, and Win Brown. "Voluntary, human rights-based family planning: A conceptual framework," Studies in Family Planning 45(1): 1-18.

Hazra, Avishek and Subrata Lahiri. 2013. "Social health insurance and social security in Uttarakhand," in T.V. Sekher, Abhishek Singh, and Sulabha Parasuraman (eds.), Population, Health and Development: Perspectives on Uttarakhand. New Delhi: Academic Foundation.

Hena, Ismat Ara, Ubaidur Rob, Nargis Sultana, Md. Irfan Hossain, Reena Yasmin, Tapash Ranjan Das, and Farid Uddin Ahmed. 2013. "Introducing medical MR in Bangladesh: MRM final report," STEP UP Research Report. Dhaka: Population Council.

Huang, Yong-mei, Ruth B. Merkatz, Jian-Zhong Kang, Kevin Roberts, Xiao-Yu Hu, Francis Di Donato, Regine Sitruk-Ware, and Li-nan Cheng. 2012. "Postpartum unintended pregnancy and contraception practice among rural-to-urban migrant women in Shanghai," Contraception 86(6): 731-738

Jain, Anrudh K. 2013. Erratum to "Hormonal contraception and HIV acquisition risk: implications for individual users and public policies" [Contraception 86 (20120) 645-652], Contraception 88(1): 195 
Jiang, Leiwen and Karen Hardee. "Women's education, family planning, or both? Application of multistate demographic projections in India," International Journal of Population Research vol. 2014 (Article ID 940509).

"Journee de dialogue sur la contraception d'urgence (CU)," meeting report. Dakar: Population Council, 2013.

Juma, Milka, Jane Alaii, L. Kay Bartholomew, Ian Askew, and Bart van den Borne. 2013. "Understanding orphan and non-orphan adolescents' sexual risks in the context of poverty: A qualitative study in Nyanza Province, Kenya," BMC International Health and Human Rights 13: 32.

Juma, Milka, Ian Askew, Jane Alaii, L. Kay Bartholomew, and Bart van den Borne. "Cultural practices and sexual risk behaviour among adolescent orphans and non-orphans: A qualitative study on perceptions from a community in western Kenya," BMC Public Health 14: 84.

Kalyanwala, Shveta, Rajib Acharya, and A.J. Francis Zavier. 2013. "Does adoption and continuation of contraception following medical or surgical abortion differ? Evidence from Bihar and Jharkhand, India," Programme Brief New Delhi: Population Council.

Keya, Kaji T., Md. Moshiur Rahman, Ubaidur Rob, and Benjamin Bellows. 2013. "Distance travelled and cost of transport for use of facility-based maternity services in rural Bangladesh: a cross-sectional survey," The Lancet 382(Supplement 1): 17.

Khan, M.E., Mario Mosquera-Vasquez, Paolo Mefalopulus, Arupendra Mozumdar, and Rachana Sharma. 2013. Social and Behavioral Change Interventions Implemented in South Asia: Evidence From Literature Search. New Delhi: Population Council and UNICEF.

Lie, Pearl P.Y., Chuen-yan Cheng, and Dolores D. Mruk 2013. "Signalling pathways regulating the blood-testis barrier," International Journal of Biochemistry and Cell Biology 45(3): 621-625

Lim, Soo, Hak Chul Jang, Kyong Soo Park, Sung II Cho, ManGyoon Lee, Hyojee Joung, Arupendra Mozumdar, and Gary Liguori. 2013. "Changes in metabolic syndrome in American and Korean Youth, 1997-2008," Pediatrics 131(1): e214-e222.

Mayer Hashi Project. 2013. "Reaching young married couples in Bangladesh: An underserved population for long-acting methods of contraception," RESPOND Project Brief no. 18. New York: EngenderHealth (The RESPOND Project).

Morgan, Lindsay, Mary Ellen Stanton, Elizabeth S. Higgs, Robert L. Balster, Benjamin Bellows, Neal Brandes, Alison B. Comfort, Rena Eichler, Amanda Glassman, Laurel Hatt, Claudia M. Conlon, and Marge Koblinsky. 2013. "Financial incentives and maternal health: Where do we go from here?" Journal of Health, Population and Nutrition 31(4): S8-S22.

Mulogo, Edgar M., Aden S. Abdulaziz, Ranieri Guerra, Benjamin Bellows, and Sebastian 0. Baine. 2012. "Self reported risk reduction behavior associated with HIV testing and counseling: A comparative analysis of facility- and homebased models in rural Uganda," AIDS Care 25(7): 835-842.

Ndigwa, Charity, Timothy Abuya, Richard Mutemwa, James Kelly Kimani, Manuela Colombini, Susannah H. Mayhew, Averie Baird, Ruth Wayua Muia, Jackline Kivunaga, and Charlotte Warren. "Exploring experiences in peer mentoring as a strategy for capacity building in sexual reproductive health and HIV service integration in Kenya," BMC Health Services Research 14(98).

Nguyen Thanh Liem, Ha Anh Duc, and Peter C. Miller (eds.). 2013. Health and Utilization of Health Services of the Poor Ethnic Minorities, and Women in Thai Nguyen, Viet Nam. Hanoi: The Culture and Information Publishing House.
Obare, Francis, Anke van der Kwaak, and Harriet Birungi. 2012. "Factors associated with unintended pregnancy, poor birth outcomes and post-partum contraceptive use among HIV-positive female adolescents in Kenya," BMC Women's Health 12: 34.

Obare, Francis, Charlotte Warren, Timothy Abuya, Ian Askew, and Benjamin Bellows. "Assessing the population-level impact of vouchers on access to health facility delivery for women in Kenya," Social Science and Medicine 102: 183-189.

. 2013. "Population-level impact of vouchers on access to health facility delivery for women in Kenya: A quasi-experimental study," The Lancet 381: s100.

Okal, Jerry, Lucy Kanya, Francis Obare, Rebecca Njuki, Timothy Abuya, Teresah Bange, Charlotte Warren, Ian Askew, and Benjamin Bellows. 2013. "An assessment of opportunities and challenges for public sector involvement in the maternal health voucher program in Uganda," Health Research Policy and Systems 11(1): 38.

Qian, Xiao-jing, Yan Ho Cheng, Pranitha Jenardhanan, Dolores D. Mruk, Premendu P. Mathur, Weiliang Xia, Bruno Silvestrini, and Chuen-yan Cheng. 2013. "Adjudin disrupts spermatogenesis by targeting drug transporters: Lesson from the breast cancer resistance protein (BCRP)," Spermatogenesis 3(2): e24993.

Qian, Xiao-jing, Dolores D. Mruk, and Chuen-yan Cheng. 2013. "Rai14 (Retinoic Acid Induced Protein 14) is involved in regulating F-Actin dynamics at the ectoplasmic specialization in the rat testis," PLOS ONE 8(4): e60656.

Qian, Xiao-jing, Dolores D. Mruk, Elissa W.P. Wong, and Chuen-yan Cheng. 2013. "Breast cancer resistance protein regulates apical ectoplasmic specialization dynamics stage specifically in the rat testis," American Journal of Physiology: Endocrinology and Metabolism 304(7): E757-E769.

Rahman, Md. Moshiur, Ubaidur Rob, Forhana Rahman Noor, and Benjamin Bellows. 2013. "Out-of-pocket expenses for maternity care in rural Bangladesh: A publicprivate comparison," International Quarterly of Community Health Education 33(2): 143-157.

Roth, Mara Y., Niloufar Ilani, Christina Wang, Stephanie T. Page, William J. Bremner, Ronald S. Swerdloff, Clint Dart, Regine Sitruk-Ware, Narender Kumar, Diana Blithe, and John K. Amory. 2013. "Characteristics associated with suppression of spermatogenesis in a male hormonal contraceptive trial using testosterone and Nestorone ${ }^{\circledR}$ gels," Andrology 1(6): 899-905.

Roy, Subrata Kumar, Sujata K. Chakraborty, and Arupendra Mozumdar. 2013. "Health: Cognition and threshold among the Oraon tea garden labourers of Jalpaiguri District, West Bengal," Journal of Anthropology, Article ID 987584.

Ruiz, Marta Julia, Marieke G. van Dijk, Karla Berdichevsky, Alejandra Munguia, Courtney Burks, and Sandra G. Garcia. "Barriers to the use of maternity waiting homes in indigenous regions of Guatemala: A study of users' and community members' perceptions," Culture, Health and Sexuality 15(2): 205-218.

Schumacher, Michael, Claudia Mattern, Abdel M. Ghoumari, J.P. Oudinet, Florencia Labombarda, Regine Sitruk-Ware, Alejandro De Nicola, and Rachida Guennoun. "Revisiting the roles of progesterone and allopregnanolone in the nervous system: Resurgence of the progesterone receptors," Progress in Neurobiology 113: 6-39.

Sitruk-Ware, Regine and Martine El-Etr. 2013.

"Progesterone and related progestins: Potential new health benefits," Climacteric 16(S1): 69-78.
Sitruk-Ware, Regine and Anita Nath. 2013. "Characteristics and metabolic effects of estrogen and progestins contained in oral contraceptive pills," Best Practice \& Research Clinical Endocrinology \& Metabolism 27(1): 13-24.

Su, Wenhui, Dolores D. Mruk, and Chuen-yan Cheng. 2013. "Regulation of actin dynamics and protein trafficking during spermatogenesis - Insights into a complex process," Critical Reviews in Biochemistry and Molecular Biology 48(2): 153-172.

Swaziland Action Group Against Abuse (SWAGAA). 2013. "Effectiveness of a comprehensive sexual and gender-based violence prevention project for in-school girls in Swaziland." Manzini, Swaziland: SWAGAA

Tapsoba, Placide, Dalomi Bahan, Emily Forsyth Queen, Gisele Kabore, and Sally Hughes. 2013. "Quality of care and client willingness to pay for family planning services at Marie Stopes International in Burkina Faso." Ouagadougou: Population Council.

Tukur, Jamilu, Babatunde Ahonsi, Salisu Mohammed Ishaku, Idowu Araoyinbo, Ekechi Okereke, and Ayodeji Oginni Babatunde. 2012. "Maternal and fetal outcomes after introduction of magnesium sulphate for treatment of preeclampsia and eclampsia in selected secondary facilities: A low-cost intervention," Maternal and Child Health Journal 17(7): 1191-1198

Wan, Hin Ting, Dolores D. Mruk, Stephen Y.T. Li, KaWai Mok, Will M. Lee, Chris K.C. Wong, and Chuen-yan Cheng. 2013. "p-FAK-Tyr ${ }^{397}$ regulates spermatid adhesion in the rat testis via its effects on F-actin organization at the ectoplasmic specialization," American Journal of Physiology: Endocrinology and Metabolism 305(6): E687-E699.

Wan, Hin Ting, Dolores D. Mruk, Chris K. C. Wong, and Chuen-yan Cheng. "Perfluorooctanesulfonate (PFOS) perturbs male rat Sertoli cell blood-testis barrier function by affecting F-actin organization via p-FAK-Tyr ${ }^{407}$ : An in vitro study," Endocrinology 155(1): 249-262.

Warren, Charlotte, Timothy Abuya, and Ian Askew. 2013. "Family planning practices and pregnancy intentions among HIV-positive and HIV-negative postpartum women in Swaziland: A cross sectional survey," BMC Pregnancy and Childbirth 13(150)

Xie, Qian Reuben, Yewei Liu, Jiaxiang Shao, Jian Yang, Tengyuan Liu, Tingting Zhang, Boshi Wang, Dolores D. Mruk, Bruno Silvestrini, Chuen-yan Cheng, and Weiliang Xia. 2013. "Male contraceptive Adjudin is a potential anticancer drug," Biochemical Pharmacology 85(3): 345-355.

\section{OTHER}

Population and Development Review 40(1)

Studies in Family Planning 45(1) 


\section{POPULATION BRIEFS}

Population Briefs is a research newsletter of the Population Council.

The Population Council confronts critical health and development issues - from stopping the spread of HIV to improving reproductive health and ensuring that young people lead full and productive lives. Through biomedical, social science, and public health research in 50 countries, we work with our partners to deliver solutions that lead to more effective policies, programs, and technologies that improve lives around the world. Established in 1952 and headquartered in New York, the Council is a nongovernmental, nonprofit organization governed by an international board of trustees.

\section{Population Council}

One Dag Hammarskjold Plaza

New York, New York 10017

popcouncil.org

Editor: Gina Duclayan

Writer: Jeff Hoover

Editorial Board: Melanie Boyer, Sasha Gruber, and Erin Kiernon

Design and Production Manager: Mike Vosika

Copyeditor: Robert Heidel

Editorial Assistant and Circulation: Debra Warn

Photos: page 9: Ivan Mateev; all others: Population Council staff.

Population Briefs is distributed without charge. Information in this newsletter may be reproduced without permission, provided it is distributed without charge and the source is acknowledged.

To receive updates from the Population Council, including when a new issue of Population Briefs is posted to our Web site, click "Subscribe" on our homepage: popcouncil.org

ISSN 1084-6786

(C) 2014 The Population Council, Inc.

Printed on recycled paper.

Council researchers in Africa are determining the acceptability of the progesterone contraceptive vaginal ring among breastfeeding women, their partners, and providers. 